\title{
Yürüyüşün Kinetik ve Kinematiği
}

\author{
Prof.Dr. Serap Alsancak \\ Ankara Üniversitesi Sağlık Hizmetleri Meslek Yüksekokulu \\ Fatih Caddesi, 197/A, Keçiören, Ankara \\ e-mail: alsancak@ankara.edu.tr
}

\begin{abstract}
Özet
Bu yazıda yürüyüş ile yürüyüş kinetik ve kinematik değerleri tanımlanarak kinezyoloji, protez, ortez, rehabilitasyon dersleri alan üniversite öğrencilerimize bilimsel temel oluşturmak ve protez-ortez alanında çalışan ekip elemanlarına yapacakları hizmette katkı sağlamak amaçlanmıştır.
\end{abstract}

Anahtar kelimeler: Yürüyüş, yürüyüş kinetiği, yürüyüş kinematiği

\section{Summary}

The aim of this article in defining of gait with gait kinetics and kinematics is to provide and create scientific basis to the university students' courses such as kinesiology, prosthetics, orthotics, rehabilitation to contribute to the working team members' services in the prosthetic and orthotic field.

Key words: Gait, gait kinetics, gait kinematics

\section{Initial contact}

Normal yürüyüşte ilk temasın olduğu topuk basışı sırasında kalça maksimum fleksiyonda $30^{\circ}$, diz ekstansiyonda ve ayak bileği nötral pozisyonda, genellikle bir miktar supinasyonda (inversiyon, adduksiyon veya varusta)' ${ }^{\prime \prime r}$. $^{24-6}$

Yer reaksiyon kuvveti kalçanın anteriorundan geçtiği için kalça ekstansörleri (gluteus maksimus ve hamstring kasları) kalça stabilizasyonunu devam ettirmek için kasılır. Dizin anteriorundan geçen yer reaksiyon kuvveti ekstansör moment oluşturur ve bu hamstring aktivitesi ile karşılanır. Bu initial contact (IC)'ta da ayak bileği posteriorunda konumlanan yer reaksiyonu ayak dorsi fleksörleri ile nötral pozisyonda tutulur. Murray tarafından IC esnasında dirseğin $8^{0}$ ve omuzun $45^{0}$ fleksiyona gittiği tanımlanmıştır. ${ }^{7}$

\section{Loading responce}

Yüklenmeye cevap fazında yürüyüş̧e öne ilerleme devam ederken ağırlık aktarımı ve şok absorbsiyonuna geçiş başlatılır. Yer reaksiyon kuvveti kalça eklemi anteriorundan geçer ve kalça ekstansörleri aktiftir. Kalça ekstansörlerindeki kasılma kontrolsüz kalça fleksiyonunu önler. Kalça ekstansör aktivitesi terminal stance'e kadar sürer. Diz IC'da tama yakın ekstansiyondadır. Ancak loading responce (LR)'da dizin fleksiyona gidişi başlar ve bu fleksiyon quadriceps kasının eccentric kasılması ile kontrollü yapılır, daha fazla fleksiyon açısına ulaşması önlenir ki bu $20^{\circ}$ yi aşmayan bir değerdir. LR'da heel rocker veya initial rocker da denir ve ayakta plantar fleksiyonun gerçekleştiği bir 
aşamadır. Ancak bu tibialis anterior kasının eccentric konraksiyonu ile kontrollü biçimde yapılır ve gerçekleşen plantar fleksiyon $10^{0}$ yi geçmez..$^{2,4,5}$

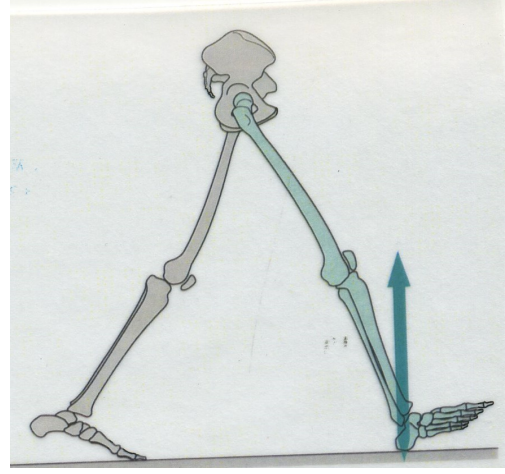

Şekil 1

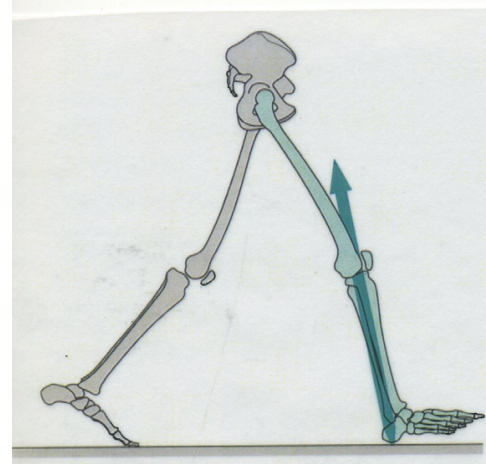

Şekil 2

(Whittle’s Gait Analysis'den alınmıştır)

\section{Opposite toe off}

Karşı ayağın yerden uzaklaştığı fazda öndeki ekstremitede kalça $25^{0}$ fleksiyondadır ve bu esnada gluteus maksimus ve hamstring kasları konsantrik kasılırlar. Karşı ekstremitede diz fleksiyonuna devam ederken, öndeki diz mid-stance öncesi bir miktar fleksiyon konumundadır ki bu ekstansiyona doğru yönlenecektir. Stance'deki diz fleksiyonu yürüyüş hızlandıkça artar, yavaşladıkça azalır. Quadriceps önce eksentrik sonra konsantrik kontraksiyon yapar. Bu esnada karşı ayak toe off' da iken öndeki ayak foot flat'dedir, plantar fleksiyondan dorsi fleksiyona geçer. Bu esnada tibialis anterior kontraksiyonu triceps surae kontraksiyonu ile yer değiştirir. Her iki ayak pronasyondadır. Karş1 ekstremite internal tibial torsiyondadir. ${ }^{2,4-6}$

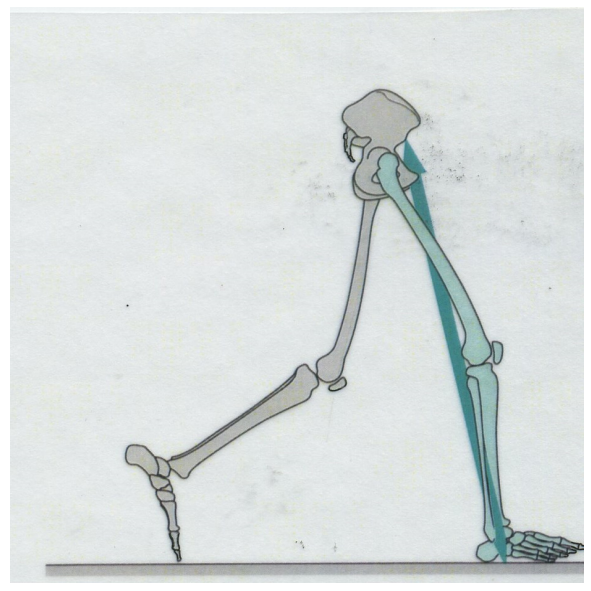

Şekil 3

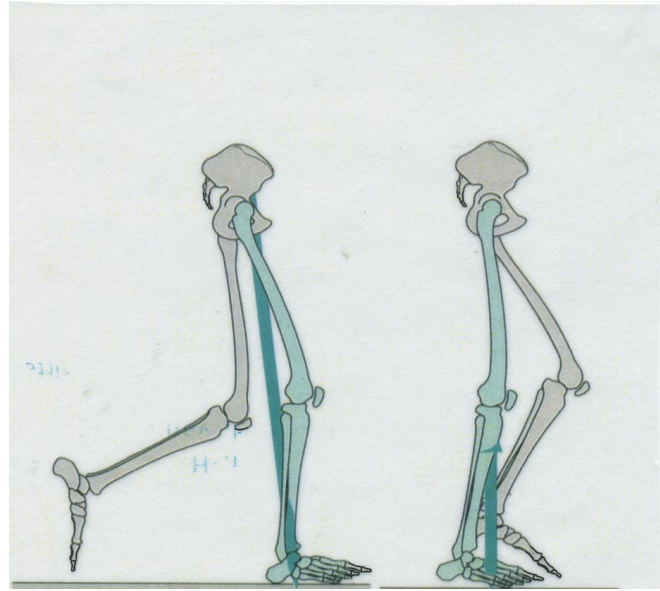

Şekil 4

(Whittle's Gait Analysis'den alınmıştır)

\section{Heel rise}

Heel rise ve terminal stance'de kalça ekstansiyonu devam eder. Bu esnada karşı ekstremite initial contact'a doğru gider, pelvisin stabilizasyonu için kalça abduktörlerinin aktivasyonuna gereksinim olur ve initial contact'a kadar devam eder. Yer reaksiyon kuvveti ayak bileğinin önüne kayar, diz maksimum ekstansiyondadır ve ayak plantar fleksörlerini aktif konuma getirir. Buradan bazı patalojik 
yürüyüşlerde dizin ekstansiyonu ile plantar fleksiyon veya dorsi fleksiyonu arasında ilişkisi vardır. Soleusun aktivasyonu ile diz hiperekstansiyonu önlenir ve diz fleksiyonu başlar. Heel rise fazında başlangıçta ayak bileği maksimum dorsi fleksiyona ulaşır. Terminal stance'in sonunda diz fleksiyonu ile birlikte ayak plantar fleksiyonu gerçekleşir. Bu esnada tibia eksternal rotasyona yönlenirken ayak supinasyondadır. Topuk yükseldiğinde ayak parmakları yere temas ederken metatarsofalangeal (MTP) eklemler ekstansiyona yönlenir. Bu 'metatarsal break veya toe break' olarak tanmlanır. $\mathrm{Bu}$ esnada hindfoot inversiyonda (adduksiyon veya varusta)' dır., ${ }^{2,-6}$

\section{Opposite initial contact}

$\mathrm{Bu}$ esnada sol omuz ve kol sağ üst ekstremiteden daha öndedir, gövde sağa rotasyon yaparken, sol pelvis ilerdedir. Kalça $10^{\circ}-20^{\circ}$ lik maksimum ekstansiyon konumuna ulaşır. Kalça ekstansiyonu ile adduktör longus'un aktivasyonu primer kalça fleksörlerinin; kalça ligamentlerinin gerilmesi ve gravitenin etkisi ile kalça fleksiyonunun başlatılmasında etkili olur. ${ }^{9,10}$ Karşı ekstremite initial contact'a geçerken yerin reaksiyonel kuvveti dizin arkasına geçer, dizin fleksiyonuna yardımcı olur ve rectus femorisin (quadricepsi içine alan) eccentric kontraksiyonu başlar. Kalçanın bulunduğu bu konum 'pull off' şeklinde de tanımlanır ve dizin fleksiyonu ile pre-swing başlar. Karşı ekstremitenin initial contact'ının öncesi ayak toe off'la yerden uzaklaşır, triceps surae'nin concentric kontraksiyonuna bağlı olarak ayak bileği plantar fleksiyona gider. MTP eklemlerde parmakların ekstansiyonu devam eder ve bu durum plantar fascia'da gerginliğe yol açar. Ayak maksimum supinasyona ulaşır ve ayağın hind foot bölümü inversiyonda (adduksiyon veya varusta) iken tibia eksternal rotasyona gider. Değişik faktörler bu esnada midtarsal eklemleri kilitleyerek ayağa yüklenmeyi sağlar ve üst düzeyde stabilizasyon gerçekleşir., ${ }^{3,4,11}$

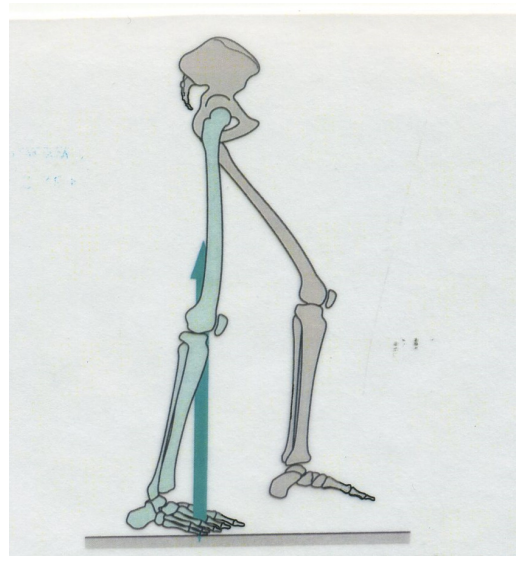

Şekil 5

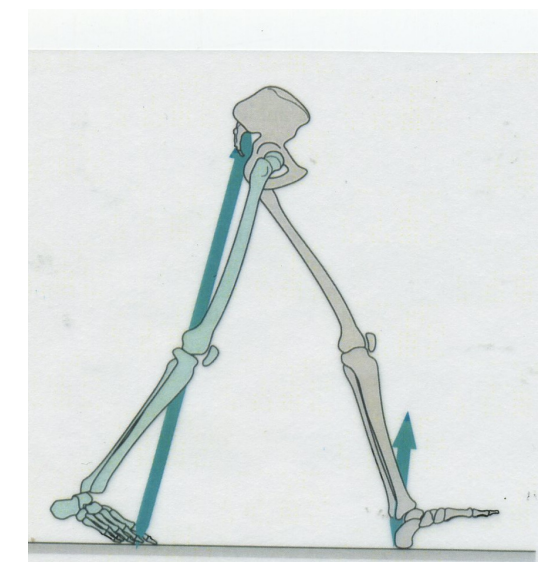

Şekil 6

(Whittle's Gait Analysis'den alınmıştır)

\section{Toe off}

Aşırı rotasyonda olan omuz, kol ve gövde nötral pozisyona geri döner. Ayak toe off'ta yerden ayrılır ve bu kalçayı fleksiona yönlendirir ve swing fazı başlatır. Bu rectus femoris ve adduktör longus kaslarının kontraksiyonu, kalça ligamentlerinde gerilim ve gravitenin etkisi ile gerçekleşir. Swing fazın başlangıcında rectus femoris özellikle hızlı yürümede aşırı diz fleksiyonunu önlemek için eccentric kontraksiyon yapar. ${ }^{8}$ Toe off'u takiben ayak bileği $25^{0}$ ye ulaşan plantar fleksiyona gider, triceps surae'nin kontraksiyonunu tibialis anteriorun aktivasyonu alır ve swing fazda ayak bileğini nötral konuma veya dorsi fleksiyona getirilir., ${ }^{2,-6}$

\section{Feet adjacent}

Sol bacağın stance'de, sağ bacağın ileri atılmak üzere solu yakaladığı bir pozisyondur. Diz $20^{0}$ fleksiyondadır, iliopsuas kasının güçlü kontraksiyonu ve gravitenin yardımı ile bu başarılır. Swing 
fazda maksimum diz $60^{\circ}-70^{\circ}$ fleksiyondadır. Hızlı yürümede diz fleksiyonu normal yürüyüş hızındakine göre daha azdır. Bu rectus femoris ve hamstringler kaslarının ko-kontraksiyonu ile sağlanır. ${ }^{1}$ Swing fazda çoğu kez ekstremite kısalması esnasında plantar fleksiyondaki ayağın tibialis anteriorun kontraksiyonu ile IC konumana geçiş için hazırlanması gerekir. Ayak IC'ye kadar çok az supinasyondadır. ${ }^{2,4-6}$

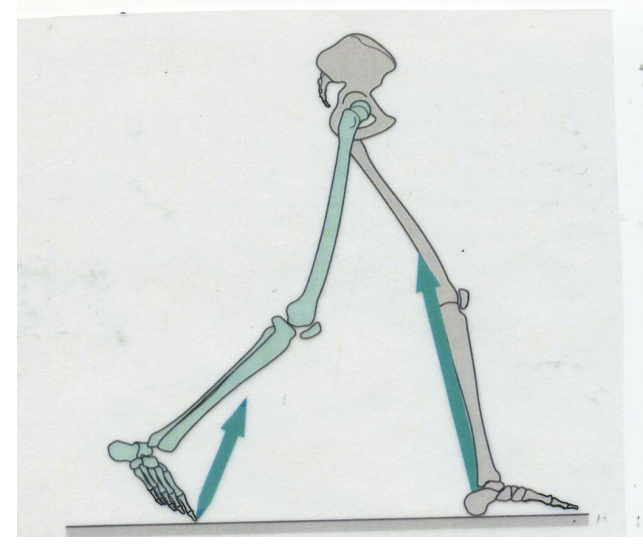

Şekil 7

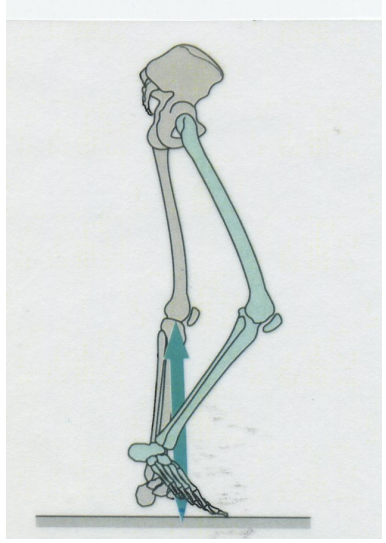

Şekil 8

\section{Vertikal tibia}

(Whittle's Gait Analysis'den alınmıştır)

Sağ ekstremite swing fazda tibia vertikal konumda iken gövde vertikal yüksekliğini kaybeder ve sol ekstremite üzerinde ilerler. Tibianın vertikal konumundan IC'a kadar kalça yaklaşık $27^{0}$ fleksiyon yapar. Kalça fleksiyon yaparken diz ekstansiyonunu limitler. Bu da terminal swing esnasında hamtring kaslarının güçlü kontraksiyonu ile olur. Swing'in sonunda dizin hiperekstansiyonu gidişi hamstring kaslarının eccentric kontraksiyonu ile önlenir. Bu esnada tibialis anterior kasılmaya devam eder, ayak bileğini pozisyonlar ve aktivite IC'a kadar sürer. ${ }^{2,4-6}$

\section{Terminal foot contact}

Yürüyüş periyodunun sonunda tekrar IC'nin başlaması için ayağın konumlanması gerekir. Çoğunlukla karışan terminolojide terminal contact yürüyüş periyodunun sonu iken aynı zamanda IC olarak bilinen başlangıcını yürüyüş periyodunun başlangıcını ifade eder. ${ }^{2,4-6}$

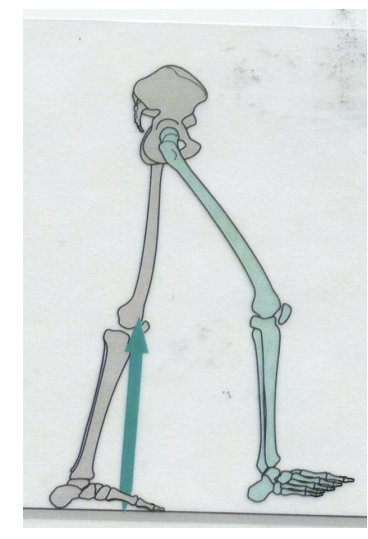

Sekil 9

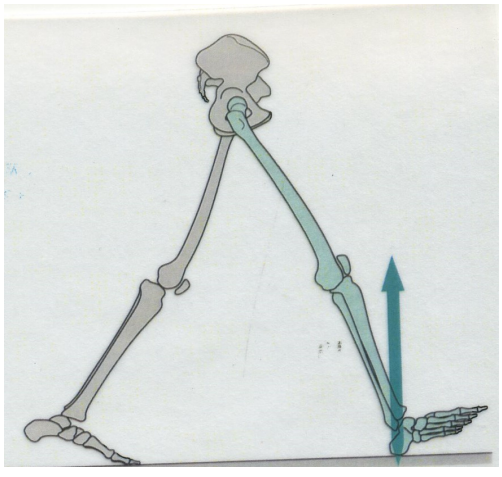

Sekil 10

(Whittle's Gait Analysis'den alınmıştır) 


\section{Yaşlara göre yürüyüş̧ değişikliği}

Cadance çocuk yürümeye başladığında yüksektir. Yetişkin değerlerine 15 yaş civarında ulaşır. Yaşla birlikte azalma olur bu özellikle 60-70 yaşlarında iyice belirginleşir. Adım boyu da bu yaşlarda azalır, yürüme genişliği artar. Aslında çocukta da adım genişliği fazladır ancak 4 yaşında yetişkin değerine ulaşır. Yaşlı bireylerde toplam kalça ve diz fleksiyon, ekstansiyon hareket genişliğinde azalma, push off sırasında ise ayağın plantar fleksiyonunda azalma olur. Stance faz 2,5 yaşın altındaki çocuklarda uzarken swing faz kısalır. Swing faz 4 yaş civarında normal değerlere ulaşır. Topuk temasını tüm çocuklarda gözlemlemek 1,5 yaşından itibaren olur ve kol salınımları da bu yaşta başlar, 4 yaşında da tüm çocuklarda gözlemek mümkündür. Çocuklarda diz fleksiyonun 2,5 yaşından sonra yetişkin değerlerine ulaştığı belirtilmektedir., ${ }^{2,4-6,12}$

\section{Kaynaklar}

1. Gage JR. The Treatment of Gait Problems in Cerebral Palsy. MacKeith Press, London, 2004.

2. Hughes J. Biomechanics and Prosthetics in Amputation. Ed. G Murdoch and B Wilson, Butterworth Heinemann, Oxford, 1996, s. 13-19.

3. Inman VT,RalstonHJ and Todd F. Human Walking. Williams and Wilkins Baltimore, 1981.

4. Jones K, Barker K. Human Movement Explained, Butterworth Heinemann, Oxford 1996, s. 297314.

5. Kernigan DC, Schaufele M, Wen MN. Gait analysis In: Rehabilitation Medicine: Principles and practice Ed. JA Delisa and BM Gans 3rd ed. Lippincott Raven Publish, Philadelphia, 1998, s. 167186.

6. Levine D, Richard J and Whittle MW. Whittle's Gait Analysis, Churchill Livingstone, Edinburgh, 2012, s. 32-39.

7. Murray MP. Gait as a total pattern of movement. Am J Phys Med. 46: 290-333.

8. Nenne A, Mayagoitia R, Veltink P. Assessment of rectus femoris function during initial swing phase. Gait Posture 9, 1-9.

9. Perry J. Normal gait. In: Atlas of Limb prosthetics: Surgical, Prosthetic and Rehabilitation Principles. Ed. JH Bowka and JW Michael. 2nd ed, Mosby Year book, St Louis, Baltimore, 1992, s. 359-371.

10. Perry J. Normal gait. In: Atlas of Amputations and Limb Deficiencies: Surgical, Prosthetic and Rehabilitation Principles. Ed. DG Smith, JW Michael, JH Bowker. 3rd ed, Rosemont, IL, s. 353365.

11. Rose J, Gamble JG. Human Walking. 3rd ed, Lippincott Williams and Wilkins, 2005.

12. Smidt GL, Wyatt MP. Rudiments of gait, Gait in children. In: Gait in Rehabilitation. Ed. GL Smidt, Churchill Livinstone, New York, 1990, s. 1-47, 157-184. 
